\title{
A historical perspective: Are inhaled corticoids sufficient to control asthma?
}

\author{
Renaud Louis, Sophie Demarche, Florence Schleich \\ Department of Respiratory Medicine, GIGA Inflammation, Immunity and Infection Research Group, CHU Liege, \\ Belgium
}

\section{ABSTRACT}

Inhaled corticoids (ICS) made a dramatic breakthrough in the management of asthma in the late eighties resulting in a sharp reduction in morbidity and mortality in the following decades. Soon after, the association between ICS and long acting $\beta 2$ agonists (LABA) soon became the gold standard of maintenance asthma treatment. With the advent of sputum induction it has become clear that asthma could not be considered as a unique entity but rather a display of several inflammatory phenotypes. Eosinophilic phenotype shows good response to ICS while non-eosinophilic, and in particular the neutrophilic phenotype, seems to be more resistant. Severe asthmatics show insufficient asthma control despite ICS/LABA. Those who are allergic and eosinophilic may benefit from add-on treatment with anti-IgE or anti-IL-5. Severe neutrophilic asthma could benefit from maintenance treatment with macrolides while thermoplasty offers some promise to those in whom airway smooth muscle hypertrophy contributes to disease instability.

Key words: inhaled corticoids; asthma; long acting $\beta 2$ agonist

\section{INTRODUCTION}

There was a time when numerous asthmatics had to be treated with systemic corticoids either on a regular basis or with repeated short courses in order to achieve asthma control. While inhaled $\beta 2$ agonists became available in the seventies it took until late eighties to have corticoids administered by the inhaled route (ICS). It was then demonstrated that regular treatment with inhaled beclomethasone and budesonide was superior to regular inhalation of short acting $\beta 2$ agonists in improving asthma symptoms and airway caliber and also reducing the use of rescue inhaled bronchodilators. It soon appeared at the population level that asthma mortality was decreasing in parallel to the increasing use of ICS. ${ }^{[1]}$

\section{THE REIGN OF THE COMBINATION ICS/} LABA IN MAINTENANCE ASTHMA TREATMENT

In the mid-nineties it became clear that adding long acting $\beta 2$ agonists (LABA) to ICS markedly improved airway caliber and symptoms, and in particular night symptoms, in those patients who remained uncontrolled with low dose of ICS. ${ }^{[2]}$ Due to their marked efficacy, the combination therapy rapidly became the gold standard of asthma treatment, and given the high prevalence of asthma in the general population, this drug association became a blockbuster in western world countries. At the same time was launched cysteinylleukotriene receptor antagonist (LTRA) as an alternative to ICS for maintenance asthma treatment in those patients who did not tolerate or were afraid of taking ICS. In randomized controlled trials (RCTs), LTRA proved to be less efficient than low dose of ICS in improving airway caliber, reducing symptoms, and controlling airway eosinophilic inflammation in asthmatics selected on the basis of a high reversibility to $\beta 2$ agonists. However, the superiority of ICS disappeared when comparing the two classes of drugs in mild to moderate asthmatics in a real-life setting where LTRA performed equally to ICS to improve asthma control and quality of life, probably because of a better 
adherence to treatment given by the oral as compared to the inhaled route. ${ }^{[3]}$

At the turn of the century it was demonstrated that the combination of ICS/LABA was particularly effective in reducing asthma exacerbation in moderate to severe asthma, both ICS and LABA contributing to this important effect. ${ }^{[4,5]}$ The combination of ICS/LABA has shown not only efficacy in RCTs but also effectiveness in real-life setting where patient selection criteria are less stringent, allowing a greater range of patients to participate. ${ }^{[6]}$

\section{VARIABLE RESPONSE TO ICS ACCORDING TO INFLAMMATORY ASTHMA PHENOTYPE}

The technique of induced sputum has been pivotal in the emergence of inflammatory phenotype concept in asthma and it has become usual to classify asthmatics according to the proportion of eosinophils and neutrophils in the airways. ${ }^{[7]}$ It appeared that while eosinophilic asthmatics display a good clinical and functional response to a fewweek treatment with ICS, it was not the same for those patients without raised eosinophilic inflammation ${ }^{[8]}$, and in particular in those with high sputum neutrophil counts, who really seemed to be insensitive to ICS. ${ }^{[?]}$

\section{THE ADVENT OF MONOCLONAL ANTIBODIES IN SEVERE ALLERGIC AND EOSINOPHILIC ASTHMA}

The concept of severe asthma has recently been reshaped in a practical way that severe asthmatics are those patients in whom control may not be achieved with or requires a combination of high dose ICS/LABA. ${ }^{[10]}$ Some biologics have proved to be efficient in those patients. The first class of drug that was shown to bring clinical benefit is monoclonal antibody directed towards IgE. Omalizumab proved to be efficient in reducing exacerbation rate and improving quality of life in severe allergic asthmatics who remained uncontrolled despite a combination of high dose ICS/LABA. ${ }^{[1]}$ Furthermore, the effectiveness of this medication has also been demonstrated in real life ${ }^{[12]}$ partly because of the "magic" and the regular follow-up imposed by the subcutaneous injection route. ${ }^{[13]}$

Similar to mild to moderate asthma, severe asthma was found to be heterogeneous with respect to the type of airway inflammation. More than half of severe asthmatics display residual eosinophilic inflammation despite receiving high dose of ICS and even oral corticoids by some of them. ${ }^{[14]}$ In those patients, increasing the dose of ICS or even giving oral corticoids results in a significant reduction of exacerbation. ${ }^{[15]}$ In those severe eosinophilic asthmatics, mepolizumab, which is an antibody directed towards interleukin (IL)-5, reduces exacerbation rate while allowing for a reduction and even a stop of oral corticoids in some patients. ${ }^{[16,17]}$ Efficacy of anti-IL-5 regarding exacerbation rate seems to be particularly related to the blood eosinophil count. It has recently been demonstrated that asthmatics who had both high blood and sputum eosinophil counts were more prone to exacerbation and poorer asthma control. ${ }^{[18]}$ The effects of anti-IL-5 on day-to-day asthma control and lung function are more controversial but shown in some studies using reslizumab. ${ }^{[16,19]}$ It has recently been shown that the effect of omalizumab in reducing exacerbation rate was essentially limited to those patients with elevated FENO (fractional ex-haled nitric oxide) and blood eosinophil counts. ${ }^{[20]}$ Monoclonal antibodies directed towards other cytokines, and in particular towards $\mathrm{TNF} \alpha$, have yielded disappointing results so far. ${ }^{[21]}$

\section{MACROLIDES AS A POSSIBLE NEW TREATMENT STRATEGY IN SEVERE NEUTROPHILIC ASTHMA}

A small number of severe asthmatics fail to show residual eosinophilic inflammation. Some of them exhibit a marked increase in neutrophil counts in the airways. In those subjects, a few-week treatment with clarithromycin may reduce the neutrophil counts and slightly improve the quality of life but fails to improve day-to-day asthma control. ${ }^{[22]}$ Long-term effect of such a treatment on asthma exacerbation remains unknown, but this point has to be clarified in the future. In this view it is worth noting that, in a pilot study, asthmatics uncontrolled with moderate to high doses of ICS and displaying a low blood eosinophil count had their exacerbation rate reduced by chronic treatment with low dose azithromycin. ${ }^{[23]}$ Effects of macrolides on severe neutrophilic asthma have to be confirmed in large scale RCTs. We can however ask whether choosing neutrophils as the main target of treatment may be a double-edged sword, as these cells play a critical role in innate immunity operating in the airways. ${ }^{[24]}$

\section{THERMOPLASTY AS A HOPE TO REVERSE AIRWAY REMODELING}

While ICS have a potent effect on eosinophilic inflammation, their ability to oppose the airway remodeling is much more controversial. Thermoplasty, a new technique that delivers high energy in the bronchi during an endoscopic procedure, may bring significant benefit there. Applying this technique three times three weeks apart has proved to be safe and has resulted in a reduction of exacerbation and hospitalization together with improved quality of life in asthmatics 
uncontrolled by a combination of ICS/LABA. ${ }^{[25,26]}$ This treatment, approved by the food and drug administration in USA, has still to make its way in Europe before becoming the official treatment for asthma. In particular it remains to determine in prospective studies which population of asthmatics may be the most suitable to benefit from this treatment procedure. As thermoplasty requires a technical expertise it is wise to limit its application to centers with experienced endoscopists.

\section{CONCLUSION}

ICS have dramatically changed the course of daily life in many asthmatics over the past decades and are responsible for the sharp reduction in asthma mortality observed since the nineties. Nevertheless, this class of drugs may not be sufficient or even inefficient in some patients. The respiratory physician dealing with asthma, and in particular with severe asthma, has to proceed with detailed functional and inflammatory investigations to better phenotype his/ her patient thereby allowing to choose the most appropriate treatment. ${ }^{[27]}$

\section{Conflicts of Interest}

None declared.

\section{REFERENCE}

1 Louis R, Schleich F, Barnes PJ. Corticosteroids: still at the frontline in asthma treatment? Clin Chest Med 2012;33:531-41.

2 Pauwels RA, Lofdahl CG, Postma DS, Tattersfield AE, O'Byrne P, Barnes PJ, et al. Effect of inhaled formoterol and budesonide on exacerbations of asthma. Formoterol and Corticosteroids Establishing Therapy (FACET) International Study Group. N Engl J Med 1997;337:1405-11.

3 Price D, Musgrave SD, Shepstone L, Hillyer EV, Sims EJ, Gilbert RF, et al. Leukotriene antagonists as first-line or add-on asthma-controller therapy. N Engl J Med 2011;364:1695-707.

4 Papi A, Corradi M, Pigeon-Francisco C, Baronio R, Siergiejko Z, Petruzzelli S, et al. Beclometasone-formoterol as maintenance and reliever treatment in patients with asthma: a double-blind, randomised controlled trial. Lancet Respir Med 2013;1:23-31.

5 Rabe KF, Atienza T, Magyar P, Larsson P, Jorup C, Lalloo UG. Effect of budesonide in combination with formoterol for reliever therapy in asthma exacerbations: a randomised controlled, double-blind study. Lancet 2006;368:744-53.

6 Louis R, Joos G, Michils A, Vandenhoven G. A comparison of budesonide/formoterol maintenance and reliever therapy vs. conventional best practice in asthma management. Int J Clin Pract 2009;63:1479-88.

7 Schleich FN, Manise M, Sele J, Henket M, Seidel L, Louis R. Distribution of sputum cellular phenotype in a large asthma cohort: predicting factors for eosinophilic vs neutrophilic inflammation. BMC Pulm Med 2013;13:11.
8 Pavord ID, Brightling CE, Woltmann G, Wardlaw AJ. Non-eosinophilic corticosteroid unresponsive asthma.Lancet 1999;353:2213-4.

9 Green RH, Brightling CE, Woltmann G, Parker D, Wardlaw AJ, Pavord ID. Analysis of induced sputum in adults with asthma: identification of subgroup with isolated sputum neutrophilia and poor response to inhaled corticosteroids. Thorax 2002;57:875-9.

10 Chung KF, Wenzel SE, Brozek JL, Bush A, Castro M, Sterk PJ, et al. International ERS/ATS guidelines on definition, evaluation and treatment of severe asthma. Eur Respir J 2014;43:343-73.

11 Humbert M, Beasley R, Ayres J, Slavin R, Hebert J, Bousquet J, et al. Benefits of omalizumab as add-on therapy in patients with severe persistent asthma who are inadequately controlled despite best available therapy (GINA 2002 step 4 treatment): INNOVATE. Allergy 2005;60:309-16.

12 Brusselle G, Michils A, Louis R, Dupont L, Van de Maele B, Delobbe $\mathrm{A}$, et al. "Real-life" effectiveness of omalizumab in patients with severe persistent allergic asthma: The PERSIST study. Respir Med 2009;103:1633-42.

13 Louis R. Anti-IgE: a significant breakthrough in the treatment of airway allergic diseases. Allergy 2004;59:698-700.

14 Schleich F, Brusselle G, Louis R, Vandenplas O, Michils A, Pilette C, et al. Heterogeneity of phenotypes in severe asthmatics. The Belgian Severe Asthma Registry (BSAR). Respir Med 2014;108:1723-32.

15 Green RH, Brightling CE, McKenna S, Hargadon B, Parker D, Bradding $\mathrm{P}$, et al. Asthma exacerbations and sputum eosinophil counts: a randomised controlled trial. Lancet 2002;360:1715-21.

16 Bel EH, Ortega HG, Pavord ID. Glucocorticoids and mepolizumab in eosinophilic asthma. N Engl J Med 2014;371:2434.

17 Pavord ID, Korn S, Howarth P, Bleecker ER, Buhl R, Keene ON, et al. Mepolizumab for severe eosinophilic asthma (DREAM): a multicentre, double-blind, placebo-controlled trial. Lancet 2012;380:651-9.

18 Schleich FN, Chevremont A, Paulus V, Henket M, Manise M, Seidel $\mathrm{L}$, et al. Importance of concomitant local and systemic eosinophilia in uncontrolled asthma.Eur Respir J 2014;44:97-108.

19 Castro M, Mathur S, Hargreave F, Boulet LP, Xie F, Young J, et al. Reslizumab for poorly controlled, eosinophilic asthma: a randomized, placebo-controlled study. Am J Respir Crit Care Med 2011;184:1125-32.

20 Hanania NA, Wenzel S, Rosen K, Hsieh HJ, Mosesova S, Choy DF, et al. Exploring the effects of omalizumab in allergic asthma: an analysis of biomarkers in the EXTRA study. Am J Respir Crit Care Med 2013;187:804-11.

21 Schleich F, Louis R. [Targeted asthma therapies: confirmations, hopes, and disappointments]. Rev Med Liege 2012;67:14-21.

22 Simpson JL, Powell H, Boyle MJ, Scott RJ, Gibson PG. Clarithromycin targets neutrophilic airway inflammation in refractory asthma.Am J Respir Crit Care Med 2008;177:148-55.

23 Brusselle GG, Vanderstichele C, Jordens P, Deman R, Slabbynck H, Ringoet $\mathrm{V}$, et al. Azithromycin for prevention of exacerbations in severe asthma (AZISAST): a multicentre randomised double-blind placebo-controlled trial.Thorax 2013;68:322-9.

24 Louis R, Djukanovic R. Is the neutrophil a worthy target in severe asthma and chronic obstructive pulmonary disease? Clin Exp Allergy 2006;36:563-7.

25 Dombret MC, Alagha K, Philippe BL, Yves BP, Joos G, Laviolette M, et al. Bronchial thermoplasty: a new therapeutic option for the treatment of severe, uncontrolled asthma in adults.Eur Respir Rev 2014;23:510-8.

26 Heinen V, Schleich F, Duysinx B, Kirsch M, Louis R. [Bronchial thermoplasty: a real advancement in the treatment of asthma].Rev Med Suisse 2014;10:1544,1546-4,1548.

27 Louis R, Manise M, Sele J, Schleich F. [Inertia and adherence as factors influencing asthma control].Rev Med Liege 2010;65:338-42.

How to cite this article: Louis $\mathrm{R}$, et al. A historical perspective: Are inhaled corticoids sufficient to control asthma? J Transl Intern Med 2015;3:113-115 